\title{
2+ Dengue
}

\author{
Alessandro M. Baldi' ${ }^{1}$, Leonardo M. P. Moraes ${ }^{1}$, Eduarda M. S. Montiel' ${ }^{2}$, \\ Amaury A. Castro Jr. ${ }^{2}$, Ana C. G. C. Kluthcovsky ${ }^{2}$ \\ ${ }^{1}$ Câmpus de Ponta Porã - Universidade Federal de Mato Grosso do Sul (UFMS) \\ CEP 79.907-414 - Ponta Porã - MS - Brazil \\ ${ }^{2}$ Departamento de Medicina - Universidade Estadual de Ponta Grossa (UEPG) \\ CEP 84.030-900 - Ponta Grossa - PR - Brasil \\ \{alessandromurtabaldi, leo.mauro.desenv, eduarda.montiel, amaury.ufms, \\ anafabio2009\}@gmail.com
}

\begin{abstract}
Dengue is an important teaching tool in the fight against dengue. The application teaches about dengue, the mosquito and the construction of recyclable traps. Also helps the user to take care of the built trap and has the exclusive function of mapping the locations that needs educational activities about dengue.
\end{abstract}

Resumo. 2+ Dengue é uma importante ferramenta didática para o combate à dengue. O objetivo do aplicativo é ensinar sobre a Dengue, o mosquito transmissor e a construção de armadilhas recicláveis. Além disso, o aplicativo auxilia o usuário a cuidar da armadilha construída e possui a exclusiva funcionalidade de mapeamento das áreas com maiores necessidades de ações educativas sobre o tema.

\section{Introdução}

A dengue é uma doença viral que se espalha rapidamente no mundo. Segundo o ministério da saúde, a incidência aumentou 50 vezes nos últimos 50 anos, sendo que na presente década, alcançou as pequenas cidades e áreas rurais. Segundo a ONU, se estima que aproximadamente 2,5 bilhões de pessoas morram em decorrência dessa doença em países onde ela é endêmica. Na região das Américas, a doença tem se disseminado com surtos cíclicos ocorrendo a cada 3/5 anos. No Brasil, o maior surto ocorreu em 2013, com aproximadamente 2 milhões de casos notificados. De acordo com o IBGE, em Ponta Porã, Mato Grosso do Sul, foram notificados 2.821 casos de dengue $(3,9 \%$ da população) em 2007 e 662 casos (0,8\% da população) em 2010.

A doença é transmitida aos humanos por meio de picadas de mosquitos fêmeas das espécies Aedes aegypti e Aedes albopictus portadores do vírus. A reprodução do Aedes aegypti ocorre, preferencialmente, em reservatórios de águas limpas, embora essa espécie possa adaptar-se a outros tipos de criadouros, como bromélias e esgotos a céu aberto.

Diante desse problema, construiu-se um software interativo em forma de aplicativo para o aprendizado sobre a Dengue. O software possui funcionalidades de informar sobre a Dengue e o mosquito transmissor, ensinar a construir uma armadilha 
de materiais recicláveis para capturar as futuras gerações do mosquito, ajudar a acompanhar a armadilha e um questionário de perguntas e respostas. Além disso, o software também gera uma estatística para a exclusiva funcionalidade de mapeamento das áreas com maiores necessidades educativas e das áreas com as armadilhas instaladas.

Este software faz parte da família de aplicativos $2+$, aplicativos que estão em constante desenvolvimento e permitem o aprendizado sobre determinado tema em 2 minutos graças às imagens didáticas e textos reduzidos ao essencial. Os aplicativos 2+ são facilmente modificados e ampliados para outros temas/áreas, pois já há uma interface padrão construída.

Este software é gratuito e é destinado ao público em geral. Além disso, oferece um mecanismo alternativo de aprendizado, podendo ser utilizado em sala de aula.

\section{Desenvolvimento}

Foram pesquisadas informações em fontes confiáveis como Ministério da Saúde, IBGE e publicações científicas a respeito da Dengue, da armadilha construída e do Aedes aegypti. Estas informações foram utilizadas para a construção de um esboço do software em forma de desenhos.

Com o esboço em mãos, foi feita a produção de imagens para o software. As imagens foram produzidas para condizerem com o texto escrito em cada tela, tendo o intuito de reforçar a mensagem textual a partir da representação visual oferecida. Foi levado em consideração que crianças possuiriam o aplicativo, portanto as imagens produzidas são instrutivas e figuradas. Além disso, na representação de pessoas e animais foram realizados desenhos mais "animados", para cativar os jovens usuários do aplicativo.

Cada imagem foi produzida de forma simples, porém intuitiva. Foram utilizadas bordas para dividir as partes do objeto desenhado com poucas cores e degradê, tendendo aos objetos uma representação monocolor a tricolor. Para destaque, quando necessário, foram realizadas mudanças nas cores das figuras. Utilizou-se o Adobe Photoshop Versão 13.0 x64 para a produção de imagens com 250x de largura e altura, resolução de 90 pixels por polegada, modo de cores 8 bits RGB (Red, Green and Blue) e extensão PNG (Portable Network Graphics) 24 bit color com transparência de fundo.

Em posse das imagens e informações do esboço, o software foi programado utilizando o ambiente de desenvolvimento Processing em modo Android com o uso das linguagens de programação Processing e Java. Além disso, foram integradas bibliotecas de comunicação com as planilhas do Google Drive para envio e recebimento de informações, bibliotecas oficiais do SDK Android e a biblioteca Ketai para aferição dos sensores do smartphone.

O Processing, utilizado neste trabalho, é uma linguagem de programação e ambiente de desenvolvimento Open Source (de código aberto) que foi criado em 2001 
com o princípio de programar facilmente elementos artísticos em computação gráfica e que têm evoluído desde então para uma ferramenta profissional de desenvolvimento.

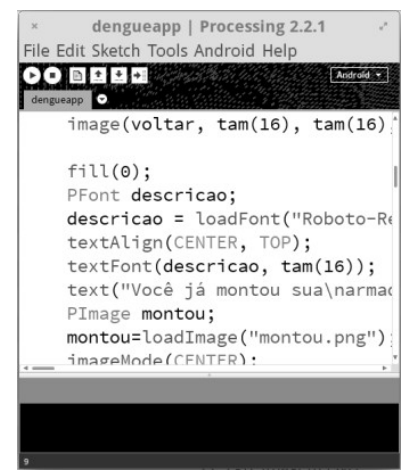

Figura 1. Processing

O aplicativo foi programado seguindo as orientações do material design (https://www.google.com/design/spec/material-design/introduction.html), nova interface padrão da Google, para que as pessoas tenham uma familiaridade ao utilizá-lo.

O aplicativo desenvolvido foi assinado digitalmente e enviado à loja de aplicativos do Android, Google Play Store, para que as pessoas possam baixá-lo e utilizá-lo.

\section{Apresentação do Software}

O software pode ser dividido em duas categorias: Software que os administradores utilizam e software que os usuários utilizam.

\subsection{Administradores}

Os administradores possuem acesso às estatísticas das respostas do questionário e das armadilhas, ao controle das perguntas e do sistema de curiosidades "Você Sabia?" graças ao exclusivo sistema de integração com as planilhas do Google Drive.

\subsubsection{Estatísticas das Respostas do Questionário}

O aplicativo do usuário, conectado à internet, envia automaticamente as estatísticas: pergunta respondida, questão respondida, número de acertos e localização. Estas estatísticas ficam na planilha do Google Drive e todos os administradores tem acesso. Graças a estas estatísticas podemos mapear as áreas com maiores necessidades educacionais e desta forma oferecer ações educacionais para melhorar a compreensão sobre o tema Dengue na área.

\subsubsection{Estatísticas das Armadilhas}

O aplicativo do usuário, conectado à internet, envia automaticamente as estatísticas de status da armadilha e localização. Estas estatísticas ficam na planilha do Google Drive e todos os administradores tem acesso. Graças a estas estatísticas podemos mapear as 
CBIE-LACLO 2015

Anais dos Workshops do IV Congresso Brasileiro de Informática na Educação (CBIE 2015)

áreas com maiores necessidades de atuação do departamento de saúde local e verificar as áreas com maiores riscos de desenvolvimento da Dengue.

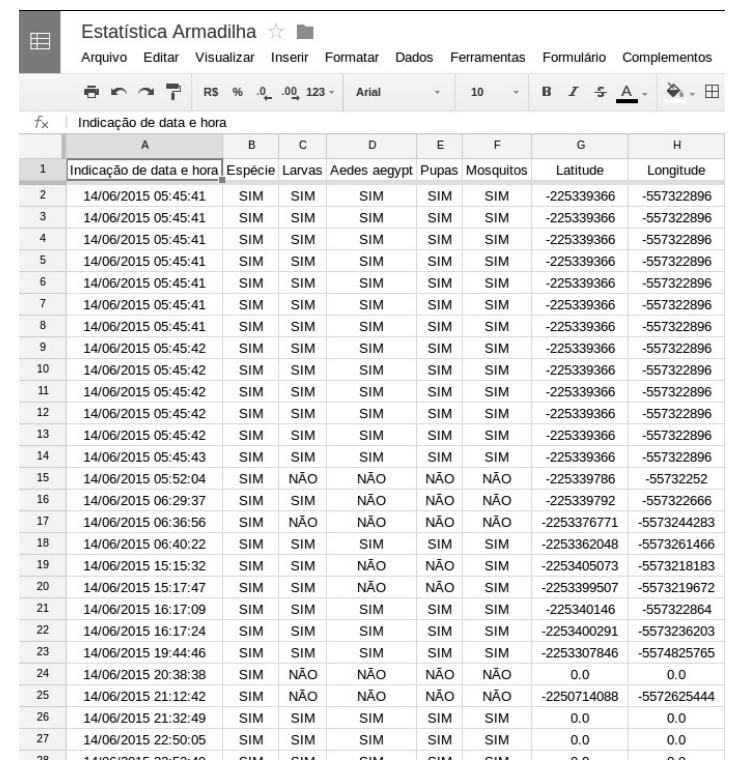

Figura 2. Tela de administração das estatísticas das armadilhas

\subsubsection{Controle das Perguntas}

Na primeira vez que o aplicativo é executado, há o download das perguntas diretamente das planilhas do Google Drive em um formato JSON escondido nos arquivos de instalação do aplicativo.

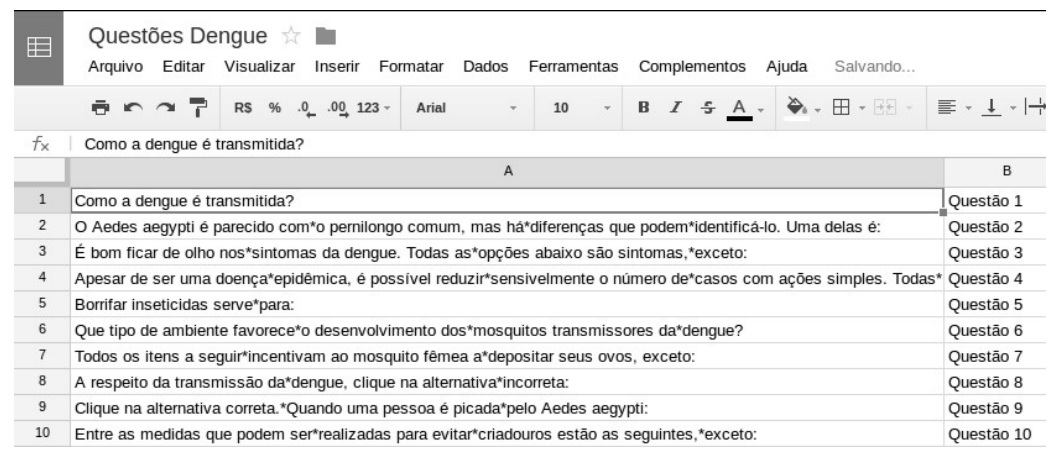

Figura 3. Tela de administração das perguntas

\subsubsection{Controle das Curiosidades (Você Sabia?)}

$\mathrm{Na}$ primeira vez que o aplicativo é executado, há o download das curiosidades diretamente das planilhas do Google Drive em um formato JSON escondido nos arquivos de instalação do aplicativo. 
CBIE-LACLO 2015

Anais dos Workshops do IV Congresso Brasileiro de Informática na Educação (CBIE 2015)

\subsection{Usuários}

Os usuários possuem acesso ao aplicativo propriamente dito, com uma interface dinâmica, construída com base no material design, com a principal funcionalidade de ensinar sobre a dengue em Geral.

Primeiramente o software carrega todas as informações das planilhas, geradas pelo administrador. Em seguida, é mostrada a funcionalidade de curiosidades aleatórias "Você Sabia?". Após o "Você Sabia?" é carregado um menu de funcionalidades e interações.

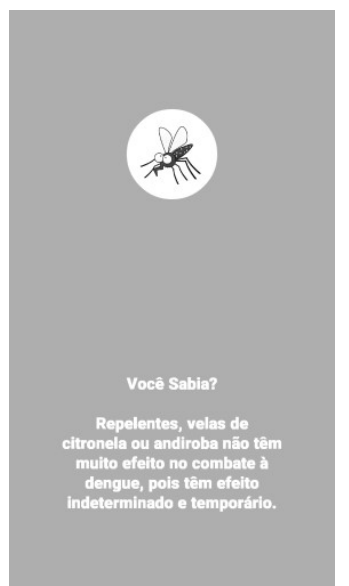

Figura 4. Tela do "Você Sabia?"

\subsubsection{Informações sobre a Dengue}

Mostra informações e imagens lúdicas sobre a dengue.

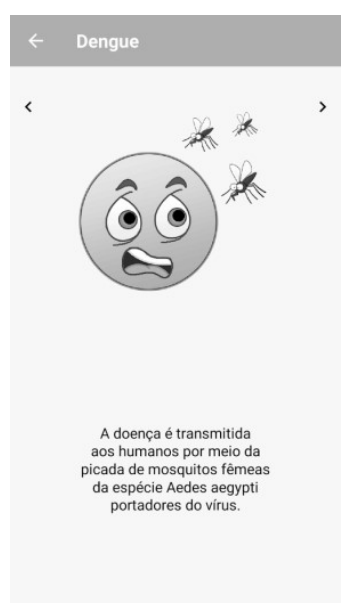

Figura 5. Tela de informações sobre a Dengue 
CBIE-LACLO 2015

Anais dos Workshops do IV Congresso Brasileiro de Informática na Educação (CBIE 2015)

\subsubsection{Informações sobre o mosquito}

Mostra informações e imagens lúdicas sobre o mosquito.

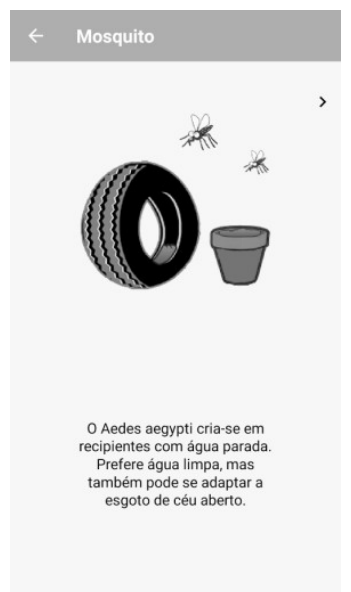

Figura 6. Tela de informações sobre o mosquito

\subsubsection{Monte a Armadilha}

Ensina a montar a armadilha da dengue com materiais recicláveis

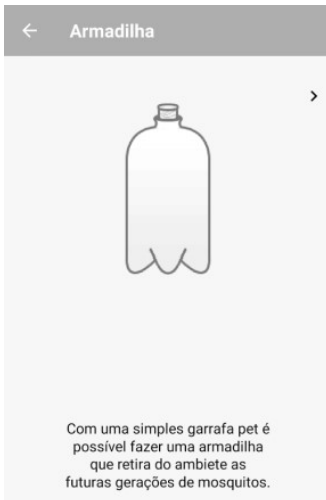

Figura 7. Tela de informações sobre a armadilha 
CBIE-LACLO 2015

Anais dos Workshops do IV Congresso Brasileiro de Informática na Educação (CBIE 2015)

\subsubsection{Acompanhe a Armadilha}

O aplicativo faz perguntas sobre o status da armadilha, dá dicas de uso e informações sobre os estágios das larvas.

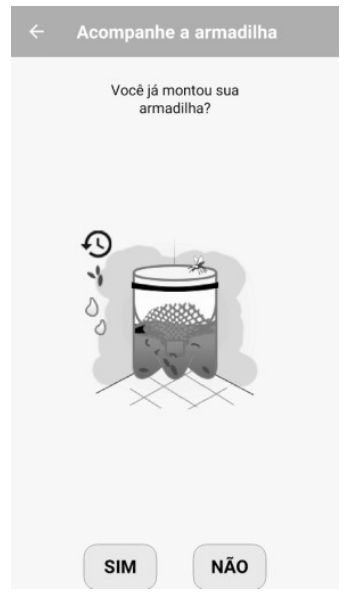

Figura 8. Tela de informações para acompanhamento da armadilha

\subsubsection{Questionário}

Perguntas aleatoriamente separadas para o usuário testar os conhecimentos sobre a Dengue.

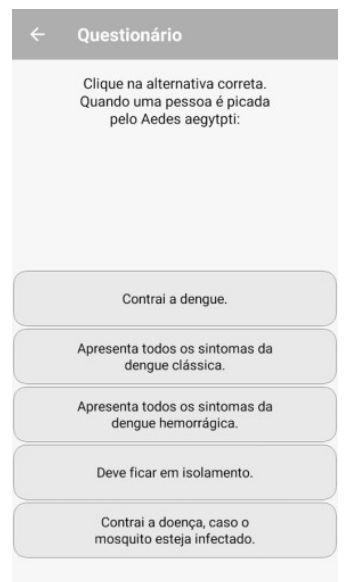

Figura 9. Tela do questionário

\section{Conclusão}

O aplicativo permite aos usuários aprender mais sobre a Dengue, construir uma armadilha para combater a Dengue e testar os conhecimentos sobre o assunto. Além disso, com a análise da situação da armadilha, permite planejar e definir as estratégias que serão adotadas para a tomada de decisão no campo da vigilância em saúde.

Os dados da armadilha, no sistema, poderão ser utilizados para a construção de um mapa cartográfico com o número de casos notificados de dengue, com base na 
CBIE-LACLO 2015

Anais dos Workshops do IV Congresso Brasileiro de Informática na Educação (CBIE 2015)

população de mosquito vetor para a doença em diversas áreas. Esse mapa poderá ser acessado pelos órgãos da vigilância em saúde, responsáveis pela proteção da saúde e defesa de uma melhor qualidade de vida para a população.

Outro objetivo indireto do software é diminuir a quantidade de lixo produzido por garrafas PET, pois as garrafas são parte da construção da armadilha, tornando o projeto sustentável.

No Brasil existem casos notificados de dengue há vários anos e a utilização do aplicativo para a construção da Armadilha para o Aedes aegypti proposto neste trabalho poderá ser uma importante ferramenta no controle da doença. 